\title{
CNS Leukemia at Diagnosis
}

National Cancer Institute

\section{Source}

National Cancer Institute. CNS Leukemia at Diagnosis. NCI Thesaurus. Code C116832.

The status of central nervous system leukemia at the time of diagnosis. 